\title{
Pseudotumour due to retained surgical sponge (gossypiboma)
}

S.M. Jarbou, ${ }^{1}$ M. AlKurdi ${ }^{1}$ and K. Al-Daod ${ }^{1}$

\section{Introduction}

The retention of gauze swabs in the peritoneal cavity is an infrequent but avoidable medical error. It can lead to serious morbidity and even mortality because it is not anticipated and is frequently misdiagnosed. Retained surgical sponge should be considered in the differential diagnosis of any postoperative patient with unresolved or unusual problems $[1,2]$.

\section{Case report}

A 31-year-old woman presented to our surgical clinic in Prince Zaid Bin Al-Hussein Hospital in April 2001 with an upper abdominal mass that had been noticeable for several months.

She was investigated and showed normal blood tests. The abdominal ultrasound showed a large mass lesion of mixed echogenicity in the mid-abdomen. Abdominal computed tomography (CT) showed a large mass lesion of heterogeneous density, containing calcification and occupying the upper mid-abdomen. This was suspected of being a teratodermoid cyst (Figure 1).

Laparotomy was performed in June 2001. A large cystic mass about $14 \times 12 \mathrm{~cm}$ with a well-defined smooth outer surface related to the greater omentum was excised (Figure 2). On opening the cyst, a surgical sponge was found inside with blue radioopaque markers which had been thought to be areas of calcification in the CT scan. (Figure 3).

The patient had undergone laparotomy and splenectomy 2.5 years earlier in October 1998 due to internal bleeding from a ruptured spleen after blunt abdominal trauma. This procedure was performed by the surgical team present in the hospital at that time. Sponge-counting measures are, and were, routinely performed before and after each procedure in the operating rooms in the hospitals of the Royal Medical Services and only X-ray detectable sponges are used. The patient had a smooth postoperative course until she presented with the abdominal mass.

After removal of the sponge, the patient recovered well and was followed-up in the clinic for about 2 years, during which time she remained in good health and was satisfied with the results of surgery.

\section{Discussion}

The actual incidence of surgical sponge retained at operation is difficult to estimate but has been reported to be 1 in every 3000

${ }^{1}$ Department of General Surgery, Prince Zaid Bin Al-Hussein Hospital, Royal Medical Services, Irbid, Jordan.

Received: 24/12/02; accepted: 21/09/03

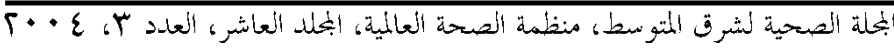




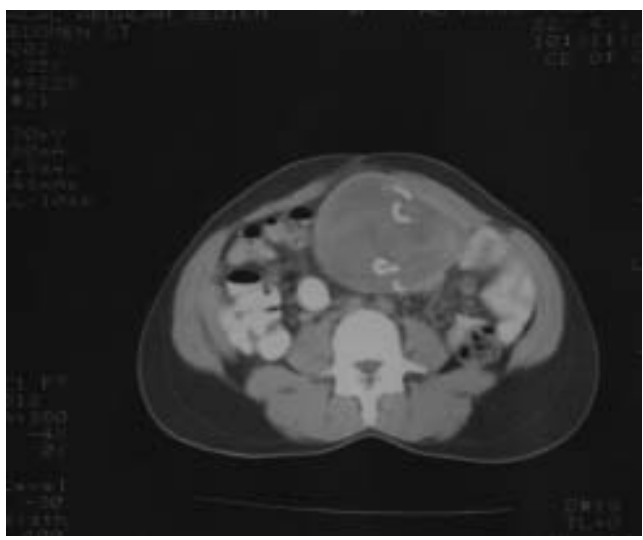

Figure 1 Abdominal computerized tomography scan showing a large cystic mass lesion with radio-opaque shadow inside

procedures [3]. This inadvertent complication most frequently occurs after gynaecological and upper abdominal surgical procedures $[3,4]$.

The preoperative diagnosis of a retained gauze swab is difficult and requires skill and experience in the analysis of the investigations performed for the patient

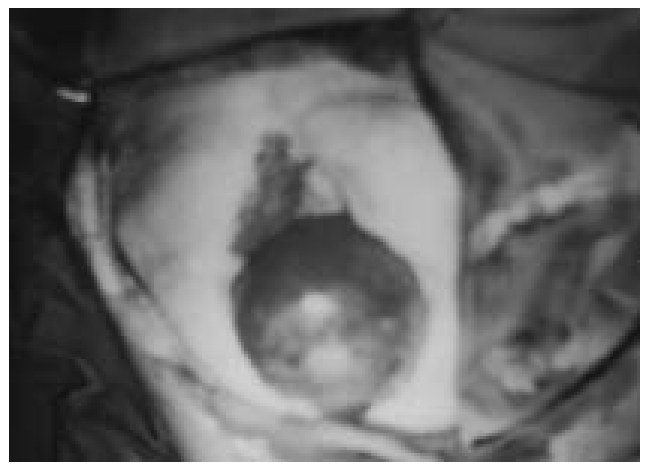

Figure 2 Large well-defined smooth surface mass when delivered through the abdominal wound

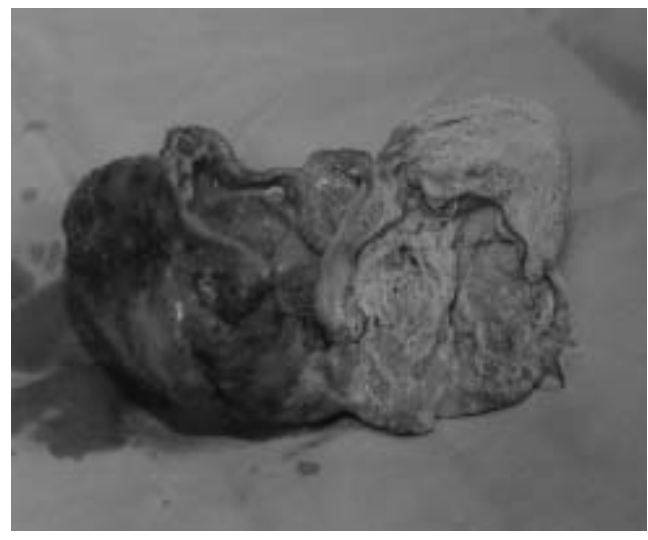

Figure 3 Opened cyst showing the forgotten sponge with the blue radio-opaque marker

[2]. Patients with forgotten intraperitoneal foreign bodies may present with pseudotumour (gossypiboma) [5,6], intestinal obstruction, erosion into the bowel or vessels, fistula formation or septic syndrome $[2,7]$. The interval between the operation and the development of symptoms in patients with retained swabs varies from a few days up to 28 years reported in a female patient aged 70 years following ureterolithotomy [3]. In our case the presentation was as pseudotumour and the interval was 2.5 years after the first operation (splenectomy).

If a patient makes a complaint about a surgical error the procedure at this hospital is as follows. The hospital will form a committee with at least two expert specialist physicians to investigate the doctor(s) and the staff nurses who performed the surgery and to decide the appropriate steps to take depending on the magnitude of complications. Penalties range from a discount in salary to a delay in promotion or both. In our case, there was no complaint from the

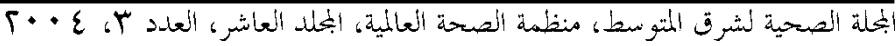


patient or her family and they were thankful to the group of doctors who saved the patient's life in the first operation and to the group of doctors who discovered and removed the foreign body from the abdomen without any further complications.

\section{Conclusion}

Despite the rarity of reports of retained surgical sponge, operating teams should take care to count swabs used in all procedures at risk for retained sponge and use only gauze swabs with radio-opaque markers. In addition, the surgeon should not unquestioningly accept correct count reports but should develop the habit of performing a brief but thorough routine postoperative wound and cavity exploration before wound closure.

\section{References}

1. Rajagobal A, Martin J. Gossypiboma 'a surgeon's legacy': report of a case and review of the literature. Diseases of the colon and rectum, 2002, 45(1):19-20.

2. Gonzalez-Ojeda A. Retained foreign bodies following intra-abdominal surgery. Hepato-gastroenterology, 1999, 46(26):808-12.

3. Botet del Castello FX et al. Diagnosis of retained abdominal gauze swabs. British journal of surgery, 1995, 82:227-8.

4. Wig JD et al. Retained surgical sponge: an unusual cause of intestinal obstruc- tion. Journal of clinical gastroenterology, 1997, 24(1):57-8.

5. Lauwers PR, Van Hee RH. Intraperitoneal gossypibomas: the need to count sponges. World journal of surgery, 2000, 24(5):521-3.

6. Sahin-Akyar G, Yagci C, Aytac S. Pseudotumor due to surgical sponge: gossypiboma. Australasian radiology, 1997, 41(3):288-91.

7. Ibrahim IM. Retained surgical sponge. Surgical endoscopy, 1995, 9(6):709-10.

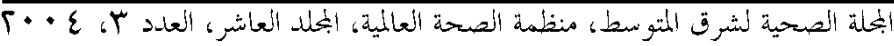

